\title{
Jugulotympanic paragangliomas in southern Finland : a 40-year experience suggests individualized surgical management
}

\section{Nicoli, Taija K.}

2017-01

Nicoli , T K, Sinkkonen, S T, Anttila , T, Makitie , A \& Jero , J 2017 , ' Jugulotympanic paragangliomas in southern Finland : a 40-year experience suggests individualized surgical management ' , European Archives of Oto-Rhino-Laryngology , vol. 274 , no. 1 , pp. 389-397 . https://doi.org/10.1007/s00405-016-4184-1

http://hdl.handle.net/10138/233879

https://doi.org/10.1007/s00405-016-4184-1

publishedVersion

Downloaded from Helda, University of Helsinki institutional repository.

This is an electronic reprint of the original article.

This reprint may differ from the original in pagination and typographic detail.

Please cite the original version. 


\title{
Jugulotympanic paragangliomas in southern Finland: a 40-year experience suggests individualized surgical management
}

\author{
Taija K. Nicoli ${ }^{1} \cdot$ Saku T. Sinkkonen ${ }^{1}$ Turkka Anttila $^{1} \cdot$ Antti Mäkitie $^{1}$ • \\ Jussi Jero ${ }^{1}$
}

Received: 7 December 2015 / Accepted: 27 June 2016/Published online: 5 July 2016

(c) Springer-Verlag Berlin Heidelberg 2016

\begin{abstract}
Treatment of jugulotympanic paragangliomas (JTPGLs) remains challenging with no clear guidelines for management or follow-up. The aim of this retrospective case-note study was to assess long-term results of operatively and conservatively managed JTPGLs between years 1974-2013. A total of 36 patients with JTPGLs were identified. Clinical characteristics and management outcomes of patients were reviewed. Data were extracted on demographics, symptoms, timing of diagnosis, tumor location and size, embolization, and management, including pre- and post-operative imaging, analysis of operative techniques, and follow-up. Pulsatile tinnitus and hearing loss were the most common presenting symptoms. Thirtyfour $(94 \%)$ patients were treated with primary surgical therapy and two $(6 \%)$ with radiotherapy. The surgical approaches included endaural approach for Fisch Class A tumors and a variety of approaches for Fisch Class B-D tumors with an increasing predilection for function-preserving surgery. Eight $(24 \%)$ patients received subtotal resection. Five $(15 \%)$ patients had a local recurrence within 10 years after primary surgery. Two $(6 \%)$ patients suffered a permanent cranial nerve $(\mathrm{CN})$ deficit after primary surgery. We advocate radical surgery when tumor resection is possible without compromising CNs. Functionpreserving surgery with at least a 10-year follow-up for Fisch Class B-D tumors should be considered if CNs are in danger.
\end{abstract}

Taija K. Nicoli

taija.nicoli@helsinki.fi

1 Head and Neck Centre, Otorhinolaryngology, Head and Neck Surgery, University of Helsinki and Helsinki University Hospital, Haartmaninkatu 4, 00029 Helsinki, HUS, Finland
Keywords Paraganglioma $\cdot$ Jugulotympanic $\cdot$ Morbidity

\section{Introduction}

Paragangliomas (PGLs) are highly vascular and largely benign tumors of neuroendocrine origin that exhibit a frequency of 1:300,000 in the head and neck area [1]. Head and neck PGLs (HNPGLs) occur in four main areas of the head and neck as tympanic, jugular, carotid body, and vagal PGLs that display their symptoms mainly by pressure effect on the nearby cranial nerves $(\mathrm{CNs})[2,3]$. PGLs are diagnosed as malignant if distant metastasis takes place; this occurs in less than $10 \%$ of HNPGLs [3-5].

B-mode and color duplex sonography, magnetic resonance imaging (MRI), and computed tomography (CT) scanning are the most common imaging techniques utilized to visualize HNPGLs. Surgery (total or subtotal resection), primary or post-operative stereotactic radiotherapy (RT), and conservative wait-and-scan strategy are examples of possible management trends for selected HNPGLs [6]. Fisch classification (Table 1) is mainly used for the preoperative treatment planning of jugulotympanic paragangliomas (JTPGLs) [7, 8]. An individual patient's age, comorbidity, size and extension of the tumor, predicted tumor growth, and pre-operative $\mathrm{CN}$ function influence potential treatment approaches.

The purpose of this study was to record the incidence of JTPGLs treated between 1974 and 2013 at Helsinki University Hospital (HUH), with a referral area that currently covers a population of approximately 1.9 million people in Finland. The emphasis was on the operative techniques used, their complications, and how they related to patients' post-operative morbidity. 
Table 1 Classification of JTPGLs according to the modified Fisch classification [8]

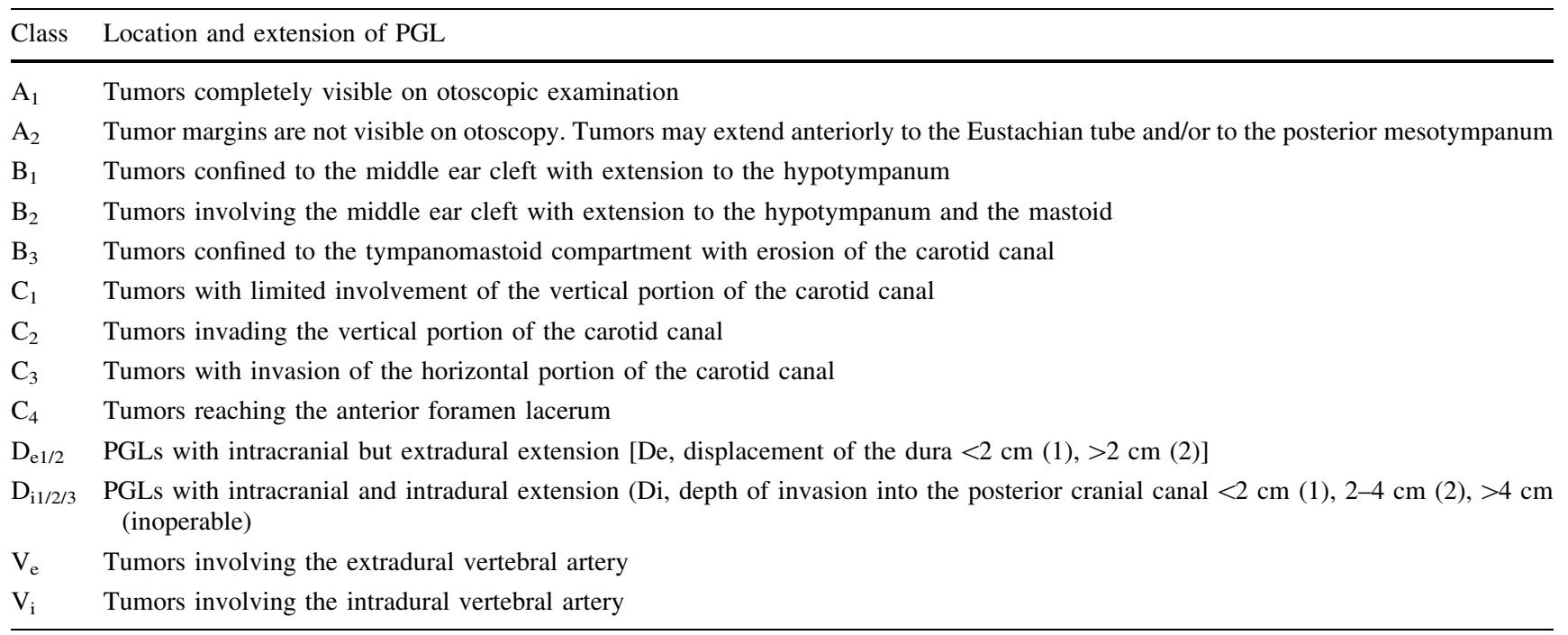

\section{Methods}

We retrospectively reviewed the clinico-radio-pathological records of all patients with a histologically confirmed JTPGL who were managed with curative intent at the HUH during a 40-year period between 1974 and 2013.

Data on age, sex, symptoms, timing of diagnosis, tumor location and quantity, embolization, Charlson's Comorbidity Index (CCI) [9], management, including pre- and post-operative imaging, and detailed analysis of operative steps, as well as follow-up were recorded. The JTPGLs were categorized according to the modified Fisch classification [8] and pre- and post-operative facial nerve function according to the House-Brackmann (H-B) scale [10].

All Fisch Class A tumors as well as the early Class B tumors were operated on by an otorhinolaryngologist. Since the 1990s, Fisch Class B-D tumors were treated at a neurosurgical department with access to a neurosurgical intensive care unit. These later tumors were operated on by a skull base surgeon/otologist unless there was intracranial extension that necessitated collaboration with a neurosurgeon.

Statistical analyses were carried out using a computerized software package (SPSS, version 22.0, Chicago, IL, USA). Institutional research permission was granted for the study protocol (Section 54, 11.03.2014). The study was also approved by the HUH Research Ethics Board (Section $25,12.03 .2014)$.

\section{Results}

\section{Patients}

A total of 36 patients with tympanic, jugular, or jugulotympanic PGLs were treated during the study period. There were $10(28 \%)$ men and $26(72 \%)$ women with an average age of 55 years (range 24-73). Seven (19\%) patients were considered to be elderly ( $>65$ years of age). At the time of diagnosis, the patients had a median CCI of 0 (range 0-3) with 20 patients having no past medical history to report. The population-based annual incidence of JTPGLs was 0.5 cases per 1,000,000 inhabitants. Genetic testing for SDHx mutations was not routinely performed.

\section{Presenting symptoms}

The main presenting symptoms were pulsatile tinnitus and hearing loss. Seven $(19 \%)$ patients presented with 1 or 2 simultaneous cranial neuropathies in CNs VII, X, XI, and XII. The presenting symptoms are outlined in Fig. 1.

\section{Pre-treatment radiological imaging}

All patients had radiological imaging before treatment. The imaging modalities included CT in $12(33 \%)$, MRI in 3 $(8 \%)$, as well as a combination of: CT + MRI in 11 $(31 \%), \mathrm{CT}+\mathrm{MRI}+\mathrm{MRA}$ in $4(11 \%), \mathrm{CT}+\mathrm{MRA}$ in 2 $(6 \%), \mathrm{CT}+$ temporal bone radiograph + carotid angiography in $1(3 \%)$, temporal bone radiograph in $1(3 \%)$, and $\mathrm{CT}+$ temporal bone radiograph + carotid angiography in $2(6 \%)$.

\section{Location of tumors and Fisch classification}

Eighteen $(50 \%)$ tumors were located in the tympanic area, $11(31 \%)$ in the jugular area, while $7(19 \%)$ tumors were considered to be jugulotympanic. Figure 2 shows tumors as per the modified Fisch classification. Urinary metanephrines and plasma chromogranin A were measured in 5 


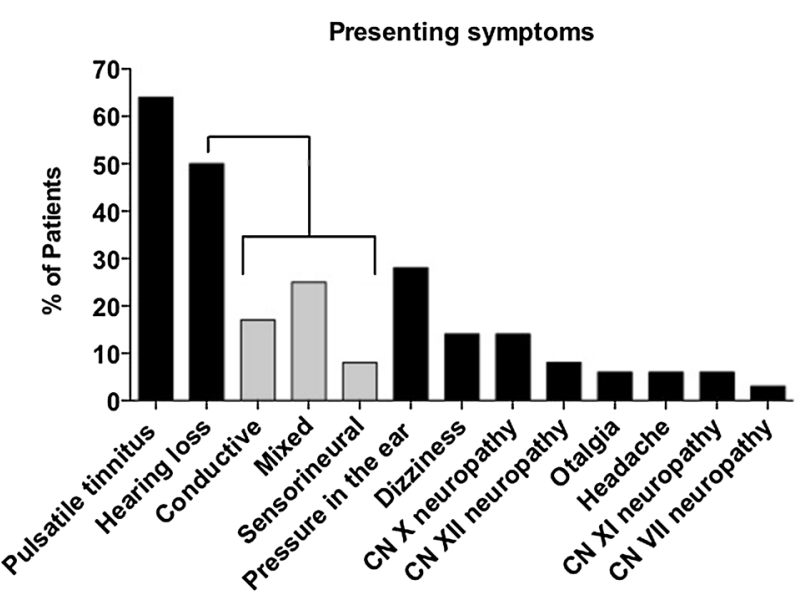

Fig. 1 Pre-treatment presenting symptoms in 36 patients with a JTPGL

(14\%) patients without a set protocol: none presented hormonal activity.

\section{Pre-operative embolization and biopsies}

Pre-operative embolization utilizing digital subtraction angiography (DSA) was used in large Fisch Class B-D tumors. Embolization, used in our clinic since 1996, was successful in eight (22\%) cases and, furthermore, attempted in two, but proved difficult due to proximal anatomy of the neck vessels or the presence of multiple feeding vessels in critical areas. There were no complications related to this procedure. In seven (19\%) patients, pre-operative biopsies of the tumor were taken.

\section{Operative and conservative management}

Thirty-four (94\%) patients were managed with primary surgical therapy, while $2(6 \%)$ patients received RT as their primary treatment. RT was chosen because of patient preference (Fisch Class $\mathrm{C}_{3}$ ) or an inoperable tumor (Fisch

Fisch classification

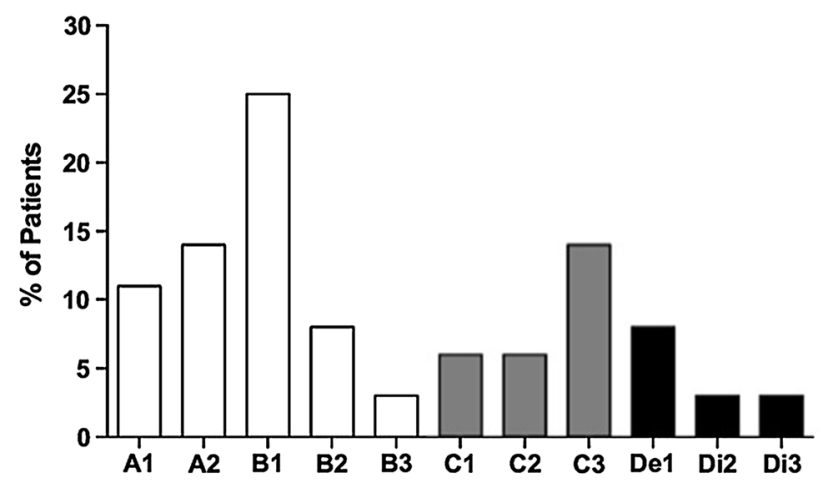

Fig. 2 Fisch classification in 36 patients with a JTPGL
Class $\mathrm{D}_{\mathrm{i} 3}$ ). For both patients, $50 \mathrm{~Gy}$ of radiation was given stereotactically in $2 \mathrm{~Gy}$ fractions. The sizes of the PGLs ranged between 2 and $13 \mathrm{~mm}$ for Class $\mathrm{A}_{1}-\mathrm{B}_{3}$ tumors and between 2 and $35 \mathrm{~mm}$ for Class $C_{1}-D_{e 2}$ tumors.

\section{Surgical approaches}

The surgical approaches included endaural approach for Fisch Class A tumors. In the 1970s and 1980s, Fisch Class B-D tumors were resected via variable surgical approaches, whereas between the 1990s and the second half of the 2000 s, the approach was via infratemporal fossa. The latter technique included transposition of the facial nerve, ligation of the sigmoid sinus, and excision of the cranial end of the jugular vein. In the last 5-10 years, facial nerve has been kept in its bony recess, the internal jugular vein ligated, and the cranial end of the sigmoid sinus packed to preserve function of the CNs. Whenever possible, the middle ear was kept intact. Table 2 outlines the intraoperative steps taken for Class $B_{1}-D_{e 2}$ tumors and the approaches used. All infratemporal fossa approach A and B tumors received $1 \mathrm{~g}$ intravenous vancomycin perioperatively. Facial nerve monitoring was routinely used in all skull-base operations.

\section{Intraoperative blood pressure, blood loss, and complications}

A sustained intraoperative blood pressure (BP) rise of $60-130 \mathrm{mmHg}$ was detected in $4(11 \%)$ patients. Twelve (33\%) patients had sustained 5-5200 $\mathrm{mL}$ of intraoperative bleeding. Six of the 12 patients had undergone pre-operative embolization; embolization was, furthermore, attempted in 1 patient. In 2 patients (Fisch Class $B_{3}$ and $D_{e}$ tumors), a 1-3 L blood loss was noted, while in another (a Fisch Class $\mathrm{D}_{\mathrm{e} 2}$ tumor), an excess of $5 \mathrm{~L}$ of blood was lost intraoperatively. All 3 patients had been embolized preoperatively and were the only ones to receive blood transfusion after primary surgery. Further intraoperative complications included a small cerebrospinal fluid leak in 1 patient.

\section{Follow-up and outcome}

The first post-operative follow-up appointment took routinely place between 1 and 2 months, the second between 2 and 4 months, and the third between 10 and 12 months. The follow-up included clinical examination and radiological imaging in selected cases. After primary surgery, 8 patients were evaluated by CT, 3 by MRI, and 6 by $\mathrm{CT}+\mathrm{MRI}$ scanning. There was no departmental guideline for the length of routine follow-up. The mean total follow- 
Table 2 Detailed operative steps taken in primary surgery in modified Fisch classification $\mathrm{B}_{1}-\mathrm{De}_{2}$ tumors

\begin{tabular}{|c|c|c|c|c|c|c|c|c|c|c|c|}
\hline $\mathrm{Pt}$ & $\begin{array}{l}\text { Fisch } \\
\text { class }\end{array}$ & $\begin{array}{l}\text { Approach } \\
(\mathrm{R} / \mathrm{S} / \mathrm{I})\end{array}$ & $\begin{array}{l}\text { Year } \\
\text { operated }\end{array}$ & $\begin{array}{l}\text { IJV } \\
\text { ligated }\end{array}$ & $\begin{array}{l}\text { SS cranial } \\
\text { end packed }\end{array}$ & $\begin{array}{l}\mathrm{CN} \text { VII kept in } \\
\text { bony recess }\end{array}$ & $\begin{array}{l}\mathrm{CN} \text { VII } \\
\text { transp }\end{array}$ & $\begin{array}{l}\text { CN IX-XII } \\
\text { exposed }\end{array}$ & $\begin{array}{l}\text { ICA } \\
\text { exposed }\end{array}$ & $\begin{array}{l}\text { VA } \\
\text { exposed }\end{array}$ & $\begin{array}{l}\text { external ear } \\
\text { closed }\end{array}$ \\
\hline$-^{\mathrm{a}}$ & $\mathrm{B}_{1}$ & EA (R) & Variable & & & $\checkmark$ & & & & & \\
\hline 20 & $\mathrm{~B}_{1}$ & RA (R) & 2000 & & & $\checkmark$ & & & & & \\
\hline 9 & $\mathrm{~B}_{1}$ & ITFB (R) & 2005 & & & $\checkmark$ & & & & & \\
\hline 33 & $\mathrm{~B}_{2}$ & TM (I) & 1986 & & & $\checkmark$ & & & & & \\
\hline 24 & $\mathrm{~B}_{2}$ & $\mathrm{TM}(\mathrm{R})$ & 1998 & & & $\checkmark$ & & & & & \\
\hline 2 & $\mathrm{~B}_{2}$ & ITFA (I) & 2009 & $\checkmark$ & $\checkmark$ & $\checkmark$ & & $\checkmark$ & $\checkmark$ & & \\
\hline 15 & $\mathrm{~B}_{3}$ & ITFB (R) & 2004 & $\checkmark$ & $\checkmark$ & $\checkmark$ & & $\checkmark$ & $\checkmark$ & & \\
\hline 31 & $\mathrm{C}_{1}$ & ITFB (R) & 1990 & $\checkmark$ & $\checkmark$ & & $\checkmark$ & $\checkmark$ & $\checkmark$ & & $\checkmark$ \\
\hline 22 & $\mathrm{C}_{1}$ & ITFA (I) & 2000 & $\checkmark$ & $\checkmark$ & & $\nu$ & $\checkmark$ & $\checkmark$ & & $\checkmark$ \\
\hline 17 & $\mathrm{C}_{2}$ & ITFA (I) & 2003 & & & $\checkmark$ & & & $\checkmark$ & & \\
\hline 19 & $\mathrm{C}_{2}$ & RS (R) & 2003 & & & $\checkmark$ & & $\checkmark$ & $\checkmark$ & $\checkmark$ & \\
\hline 28 & $\mathrm{C}_{3}$ & PS (R) & 1993 & $\checkmark$ & $\checkmark$ & $\checkmark$ & & $\checkmark$ & $\checkmark$ & & \\
\hline 10 & $\mathrm{C}_{3}$ & ITFA (I) & 2003 & & & $\checkmark$ & & & & & \\
\hline 8 & $\mathrm{C}_{3}$ & ITFB (S) & 2006 & $\checkmark$ & $\checkmark$ & $V$ & & $\checkmark$ & $\checkmark$ & $\checkmark$ & \\
\hline 1 & $\mathrm{C}_{3}$ & ITFB (S) & 2010 & $\checkmark$ & $\checkmark$ & 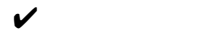 & & $\checkmark$ & $\checkmark$ & & \\
\hline 23 & $\mathrm{D}_{\mathrm{e} 1}$ & ITFB (I) & 1996 & & & $\checkmark$ & & $\checkmark$ & & & \\
\hline 21 & $\mathrm{D}_{\mathrm{e} 1}$ & PFA (R) & 2000 & & & 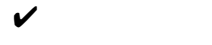 & & $\checkmark$ & & $\checkmark$ & \\
\hline 4 & $\mathrm{D}_{\mathrm{e} 1}$ & RS (I) & 2008 & $\checkmark$ & $\checkmark$ & $\checkmark$ & & $\checkmark$ & $\checkmark$ & $\checkmark$ & \\
\hline 11 & $\mathrm{D}_{\mathrm{e} 2}$ & ITFB (S) & 2005 & 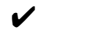 & $\checkmark$ & $\checkmark$ & & $\checkmark$ & $\checkmark$ & $\checkmark$ & \\
\hline
\end{tabular}

pt patient, class classification, IJV internal jugular vein, $S S$ sigmoid sinus, $C N$ VII facial nerve, $C N I X-X I I$ glossopharyngeal-hypoglossal nerves, $I C A$ internal carotid artery, $V A$ vertebral artery, trans transposition, $E A$ endaural, $R A$ retroauricular, $R S$ retrosigmoidal, ITFA infratemporal fossa type A, ITFB infratemporal fossa type B, TM tympanomastoidectomy, $P S$ petrosectomy, $P F A$ posterior fossa approach, $R$ radical, $S$ sparing (planned), $I$ incomplete (unplanned)

a Altogether 7 patients

up time was 6.1 years (range 0.5-37). Even if the followup period tended to be shorter for Fisch Class A and B tumors, its length depended on intraoperative findings, post-operative examination, and radiological findings, as well as patients' complaints.

The first of the two patients who received RT (Fisch Class $\mathrm{C}_{3}$ ) did not want further follow-up. Her pre-treatment complaints included $\mathrm{CN} X$ and XII palsies. One MRI was taken at 2-year post-RT, which showed no new growth of the tumor. The second patient treated with RT for her Fisch Class $\mathrm{D}_{\mathrm{i} 3}$ tumor had a 6-year history of unilateral deafness before the extensive JTPGL was discovered due to a new CN VII palsy. Before RT, the CN VII was Grade I-II. Immediately post-RT, the patient suffered new CN XII as well as Grade IV CN VII palsies. The patient was followed-up for 4 years post-RT and at the last appointment had a Grade II CN VII palsy and $\mathrm{CN}$ XII palsy with normal swallowing function. Serial CT scans showed no new growth in the tumor during the follow-up time.

One patient (Fisch Class $\mathrm{D}_{\mathrm{e} 2}$ ) died of stroke within $24 \mathrm{~h}$ following surgery due to bleeding obstructing the fourth ventricle. None of the other patients died as a direct or indirect consequence of a JTPGL.

\section{Short- and long-term post-treatment cranial nerve deficits and secondary treatment approaches}

Table 3 highlights the short- and long-term post-operative $\mathrm{CN}$ deficits, and residual and recurrent tumors, as well as the secondary treatment approaches. In eight (24\%) cases, a residual was either left in situ perioperatively (subtotal resection) or found within a 6-month post-operative period. During follow-up, 5 (15\%) patients had a local recurrence. One patient (patient 35, Table 3) had a second recurrence 14 years after primary surgery. Four out of five pre-operatively paralyzed CNs recovered their function post-operatively. Four (11\%) surgically managed patients suffered a new long-term $\mathrm{CN}$ palsy after primary surgery. Two $(6 \%)$ of the four patients were left with a permanent $\mathrm{CN}$ deficit.

Treatment modalities of short- and long-term complications after primary surgery or secondary surgery/RT are presented in Table 4. Secondary RT entailed giving 50 Gy of radiation in 2 Gy fractions stereotactically with the exception of 2 early patients (patients 33 and 35) who received external beam $\mathrm{RT}$ for tumor recurrence. Patient 21 sustained a new CN VII palsy 2 years after secondary RT. At the time, no new growth was seen in the tumor and the deficit was thought to result from a combination of the 
Table 3 Pre- and post-operative cranial nerve defects, JTPGL recurrences, and secondary treatment modalities. Short-term $(\mathrm{ST})=<6$ months, long-term $(\mathrm{LT})=>6$ months

\begin{tabular}{|c|c|c|c|c|c|c|c|c|c|c|}
\hline $\begin{array}{l}\text { PtPpp } \\
\mathrm{Pt}\end{array}$ & $\begin{array}{l}\text { Fisch } \\
\text { class }\end{array}$ & $\begin{array}{l}\mathrm{Pt} \\
\text { age }\end{array}$ & $\begin{array}{l}\text { Year } \\
\text { operated }\end{array}$ & $\begin{array}{l}\text { Pre-op CN } \\
\text { defect }\end{array}$ & $\begin{array}{l}\text { Approach } \\
(\mathrm{R} / \mathrm{S} / \mathrm{I})\end{array}$ & $\begin{array}{l}\text { Post-op prim } \\
\text { surgery ST CN } \\
\text { defect }\end{array}$ & $\begin{array}{l}\text { Post-op prim } \\
\text { surgery LT CN } \\
\text { defect }\end{array}$ & $\begin{array}{l}\text { Local } \\
\text { residual or } \\
\text { recurrence }\end{array}$ & $\begin{array}{l}\text { Secondary } \\
\text { surgery }\end{array}$ & $\begin{array}{l}\text { Secondary } \\
\mathrm{RT}^{\mathrm{e}}\end{array}$ \\
\hline $35^{\mathrm{a}}$ & $\mathrm{B}_{1}$ & 37 & 1977 & VIII (mixed) & EA (R) & & & $\boldsymbol{V}(3)$ & $\boldsymbol{\nu}(3)$ & $\boldsymbol{V}(14)$ \\
\hline 27 & $\mathrm{~B}_{1}$ & 60 & 1994 & & EA (R) & & & $\boldsymbol{V}(10)$ & $\boldsymbol{V}(10)$ & \\
\hline 7 & $\mathrm{~B}_{1}$ & 58 & 2006 & VIII (mixed) & EA (R) & VII & & & & \\
\hline 33 & $\mathrm{~B}_{2}$ & 67 & 1986 & & $\mathrm{TM}(\mathrm{I})$ & & & $\boldsymbol{V}(0)$ & $\boldsymbol{V}(0)$ & $\boldsymbol{V}(0)$ \\
\hline 2 & $\mathrm{~B}_{2}$ & 66 & 2009 & & ITFA (I) & VII, XII & & & & \\
\hline 15 & $\mathrm{~B}_{3}$ & 60 & 2004 & VIII (mixed) & ITFB (R) & & & $\boldsymbol{V}(4)$ & & $\boldsymbol{V}(8)$ \\
\hline 31 & $\mathrm{C}_{1}$ & 52 & 1990 & VIII (mixed) & ITFB (R) & VII, IX-XI & $\mathrm{XI}$ & & & \\
\hline $22^{\mathrm{b}}$ & $\mathrm{C}_{1}$ & 46 & 2000 & X, XII & ITFA (I) & VI, VII, XI & & $\boldsymbol{\checkmark}(0)$ & & \\
\hline 17 & $\mathrm{C}_{2}$ & 57 & 2003 & & ITFA (I) & & & $\boldsymbol{V}(0)$ & & $\boldsymbol{V}(9)$ \\
\hline 19 & $\mathrm{C}_{2}$ & 56 & 2003 & VIII (SNHL) & $\mathrm{RS}(\mathrm{R})$ & VII, X & VII & $\boldsymbol{V}(2)$ & & $\boldsymbol{V}(2)$ \\
\hline 28 & $\mathrm{C}_{3}$ & 50 & 1993 & VIII (SNHL) & PS (R) & IX-XI & $\mathrm{X}$ & & & \\
\hline 10 & $\mathrm{C}_{3}$ & 53 & 2003 & VIII (mixed) & ITFA (I) & & & $\boldsymbol{V}(0)$ & $\boldsymbol{V}(2)$ & $\boldsymbol{V}(5)$ \\
\hline 8 & $\mathrm{C}_{3}$ & 34 & 2006 & $\mathrm{X}, \mathrm{XI}$ & ITFB (S) & IX, X, XII & & $\boldsymbol{V}(0)$ & & $\boldsymbol{V}(0)$ \\
\hline 1 & $\mathrm{C}_{3}$ & 57 & 2010 & $\begin{array}{l}\text { VIII } \\
\text { (mixed), } \\
\text { XI }\end{array}$ & ITFB (S) & VII & & $\boldsymbol{\sim}(2)$ & & $\boldsymbol{V}(2)$ \\
\hline $23^{\mathrm{c}}$ & $\mathrm{D}_{\mathrm{e} 1}$ & 47 & 1996 & & ITFB (I) & & & $\boldsymbol{\nu}(0)$ & $\boldsymbol{V}(2)$ & \\
\hline 21 & $D_{e 1}$ & 68 & 2000 & $\mathrm{X}$ & PFA (R) & VIII-XI & $\mathrm{X}$ & $\boldsymbol{\nu}(0)$ & & $\boldsymbol{V}(4)$ \\
\hline 4 & $\mathrm{D}_{\mathrm{e} 1}$ & 53 & 2008 & & RS (I) & VIII & & $\boldsymbol{\nu}(0)$ & $\boldsymbol{V}(4)$ & \\
\hline $11^{\mathrm{d}}$ & $\mathrm{De}_{2}$ & 59 & 2005 & X, XII & ITFB (S) & & & & & \\
\hline
\end{tabular}

pt patient, class classification, $R S$ retrosigmoidal, ITFA infratemporal fossa type A, ITFB infratemporal fossa type B, $R A$ retroauricular, TM tympanomastoidectomy, $P S$ petrosectomy, $P F A$ posterior fossa approach, $E A$ endaural, $R$ radical, $S$ sparing (planned), $I$ incomplete, (unplanned), $R T$ radiotherapy, $C N$ cranial nerve, $S N H L$ sensorineural hearing loss

${ }^{a}$ Second recurrence 14 years after primary surgery

b Intraoperatively some tumor left on dura; not seen in post-operative imaging

c Altogether 5 operations: incomplete excision

${ }^{\mathrm{d}}$ Death $<24$ h post-op (stroke)

e Years after primary surgery

tumor and scars - or to be idiopathic. Patient 23 underwent altogether five operations during the study period, but some PGL still remained.

\section{Discussion}

Treatment of JTPGLs is challenging, possible post-operative morbidity is considerable, and no general guidelines for treatment or follow-up are available. Our institution's strategy includes radical surgery when complete tumor resection is possible. If $\mathrm{CNs}$ are in danger, we advocate function-preserving surgery. While subtotal tumor resection may help relieve pressure symptoms in large inoperable tumors, primary RT is another viable alternative to control local tumor growth in complex JTPGLs. This retrospective study reviews the results of our strategy with the aim of comparing them with the results in the current literature.
This study provides epidemiological, population-based data on JTPGLs managed at the HUH district during the past 40 years with a catchment area of 1.9 million people, which is approximately a third of Finland's population. The main strength of this study is the completeness of the patient data; no patient was lost to follow-up. Despite the extent of the study setting, the patient cohort remains comparatively small.

A high level of tumor control combined with minimal morbidity from CN VII-XII deficits and preservation of hearing are the main goals of JTPGL treatment. Künzel et al. recommend primary surgical resection for young patients with unilateral tumors and evident $\mathrm{CN}$ pareses [6]. When there is evidence of pre-operative lower $\mathrm{CN}$ dysfunction, Ahmad et al. [11] endorse total resection of the involved CNs followed-up by the rehabilitative surgical procedures in case poorly compensated $\mathrm{CN}$ dysfunction persists after 6 months $[11,12]$. For older patients whose 
Table 4 Short- (ST) and long-term (LT) complications and their treatment after primary and secondary surgery (age = at the time of surgery)

\begin{tabular}{|c|c|c|c|c|c|c|c|c|}
\hline $\mathrm{Pt}$ & $\begin{array}{l}\text { Fisch } \\
\text { class }\end{array}$ & Pt age & Year & $\begin{array}{l}\text { Prim } \\
\text { surgery }\end{array}$ & $\begin{array}{l}\text { Secondary } \\
\text { surgery/ } \\
\text { RT }\end{array}$ & ST complication & LT complication & Treatment/other \\
\hline 26 & $\mathrm{~A}_{1}$ & 68 & 1995 & $\checkmark$ & & & TMP & Tympanoplasty \\
\hline 32 & $\mathrm{~A}_{2}$ & 33 & 1989 & $\checkmark$ & & & TMP & Myringoplasty \\
\hline 35 & B1 & 40 & 1980 & & $\boldsymbol{V}$ & $\begin{array}{l}\text { CN VII palsy (for } \\
5 \text { months) }\end{array}$ & $\begin{array}{l}\text { Deafness of the treated } \\
\text { ear }\end{array}$ & \\
\hline 9 & $\mathrm{~B}_{1}$ & 59 & 2005 & $\boldsymbol{v}$ & & & TMP & Tympanoplasty \\
\hline 6 & $\mathrm{~B}_{1}$ & 59 & 2006 & $\checkmark$ & & & TMP & Pt refused operative treatment \\
\hline 31 & $\mathrm{C}_{1}$ & 52 & 1990 & $\boldsymbol{V}$ & & & CN XI palsy & Early retirement due to $\mathrm{CN}$ XI palsy \\
\hline 19 & $\mathrm{C}_{2}$ & 56 & 2003 & $\checkmark$ & & & CN VII palsy & $\begin{array}{l}\text { Permanent grade II (H-B) CN VII palsy } \\
\text { (minor asymmetry of one corner of } \\
\text { mouth) managed conservatively }\end{array}$ \\
\hline 28 & $\mathrm{C}_{3}$ & 50 & 1993 & $\boldsymbol{V}$ & & & CN X palsy & Thyroplasty \\
\hline 10 & $\mathrm{C}_{3}$ & 55 & 2005 & & $\checkmark$ & & CN X palsy, TMP & Injection laryngoplasty, tympanoplasty \\
\hline 8 & $\mathrm{C}_{3}$ & 34 & 2006 & $\boldsymbol{V}$ & & & CN X palsy & Thyroplasty \\
\hline 23 & $\mathrm{D}_{\mathrm{e} 1}^{\mathrm{a}}$ & 47,49 & $\begin{array}{l}1996 \\
1998\end{array}$ & & $\checkmark$ & $\begin{array}{l}\text { 1996: CN VII palsy, } \\
\text { 1998: CSF leak, } \\
\text { ICA pseudo- } \\
\text { aneurysm }\end{array}$ & & $\begin{array}{l}\text { Gold weight to upper eyelid (for CN VII } \\
\text { palsy), grafting of ICA (for ICA } \\
\text { pseudoaneurysm), CSF fistula repair } \\
\text { (gastrostomy, spinal drain, speech } \\
\text { therapy also in 1998) }\end{array}$ \\
\hline 21 & $\mathrm{D}_{\mathrm{e} 1}$ & 68,74 & $\begin{array}{l}2000, \\
2006\end{array}$ & $\boldsymbol{\nu}$ & $\boldsymbol{V}^{*}$ & $\begin{array}{l}\text { Tracheostomy (post- } \\
\text { primary surgery) }\end{array}$ & $\begin{array}{l}\text { CN X palsy (post- } \\
\text { primary surgery); } \\
\text { CN VII palsy } \\
\text { (2 years after } \mathrm{RT})\end{array}$ & $\begin{array}{l}\text { CN X palsy recovered to pre-operative } \\
\text { state over the years without } \\
\text { intervention; facial reanimation for } \\
\text { CN VII palsy }\end{array}$ \\
\hline 4 & $\mathrm{D}_{\mathrm{e} 1}$ & 57 & 2012 & & $\boldsymbol{V}$ & & $\begin{array}{l}\text { Pharyngeal constrictor } \\
\text { muscle dysfunction }\end{array}$ & Conservative treatment \\
\hline
\end{tabular}

$p t$ patient, prim primary, class classification, $R T$ radiotherapy, $S T$ short-term, $L T$ long-term, $C N$ VII facial nerve, $C N X$ vagus nerve, $C N X I$ accessory nerve, TMP tympanic membrane perforation, $H-B$ House-Brackmann scale, ICA internal carotid artery, $C S F$ cerebrospinal fluid

${ }^{a}$ Altogether 5 operations: 2 in 1996, 3 in 1998 (initially wrongly diagnosed as a meningioma)

CN function is normal and hearing satisfactory, subtotal tumor resection may suffice [12]. Willen et al. advocate limited middle ear/mastoid tumor resection followed by post-operative RT in elderly patients to minimize treatment-related morbidity, to reduce pulsatile tinnitus, and to improve residual hearing [13]. Cosetti et al. further support conservative surgical excision with vigilant long-term monitoring in patients with advanced age [14]. According to a meta-analysis by Ivan et al., patients undergoing stereotactic radiosurgery (SRS) alone experienced the lowest rates of recurrence where the incidence of CN IXXI deficits was higher in the gross-total resection group [15]. Forbes et al. note that while radiosurgery should be considered a practicable approach in the primary treatment of JTPGLs, long-term data are lacking [16]. A review by Suarez et al. comparing the efficacy and safety of surgery, external beam radiotherapy (EBRT), and SRS for jugular PGLs noted that, compared to surgery, EBRT and SRS offer lower risks of morbidity and similar chance of tumor control [17].

At our institution, patients have been offered surgical resection as the primary treatment without a set guideline; in the present cohort, only two received RT due to personal choice or an inoperable tumor. Seven patients were elderly and six of them underwent surgical treatment between the years 1986-2013. Five of the six patients had normal CN function pre-operatively with one patient presenting with a $\mathrm{CN} X$ palsy that persisted post-operatively. While none suffered a new long-term CN dysfunction post-operatively, one patient had a post-operative TMP that was consequently repaired.

In the whole cohort, altogether $2(6 \%)$ patients suffered a new permanent $\mathrm{CN}$ palsy after primary surgery. Sanna et al. report a new post-operative lower $\mathrm{CN}$ deficit rate of $54 \%$ after primary surgery in a cohort of 122 class $\mathrm{C}$ and D JTPGLs [18]. The pre-operative $\mathrm{CN}$ deficit rate was $44 \%$ in their cohort and none of the patients recovered function of the pre-operatively paralyzed CNs. The reported incidences of new post-operative lower $\mathrm{CN}$ deficits after JTPGL surgery, between 5 and $59 \%$ across the literature in the past 20 years, were also revisited [18]. A recent Spanish study further reports a $45.5 \%$ post-operative CN deficit in JTPGLs overall, rising to $100 \%$ in tumors with intradural extension [19]. The noticeably low 
incidence of post-operative $\mathrm{CN}$ deficits in our cohort can be explained by the avoidance of $\mathrm{CN}$ sacrifice in favor of subtotal tumor resection. While supporting function-preserving surgery, we stress the importance of long-term follow-up as tumor residuals and recurrences were not uncommon in our cohort. A recent study reports that if more than $80 \%$ of the pre-operative tumor volume is resected, the residual tumor seems less likely to grow [20]. Subtotal tumor resection in large inoperable tumors is also often enough to abolish patients' distressing symptoms, including pulsatile tinnitus, pressure in the ear, and headache. Subtotal tumor resection may also improve patients' residual hearing by lessening conductive hearing loss.

Pre-operative embolization of JTPGLs may reduce intraoperative blood loss and operative duration and should be carried out if possible [21, 22]. At our institution, this technique has been utilized only after 1996 and thus, in a fifth of cases in the present cohort. While embolization did not drastically affect macroscopic intraoperative blood loss, the reduction in intraoperative microscopic bleeding in embolized patients greatly improved operative visibility.

If surgery is chosen as the treatment modality of choice, Boedeker suggests transmeatal approach or an approach via mastoidectomy for Fisch Class A and B tumors [23]. In some Class B JTPGLs, juxtacondylar approach is recommended. In our cohort, all Fisch Class A tumors were resected via an endaural approach, while the approach varied for Class B tumors. In the literature, Class C and D tumors are usually resected via an infratemporal approach, although juxtacondylar approach may be necessary for Class $\mathrm{C}_{1}, \mathrm{C}_{2}$, and $\mathrm{D}_{\mathrm{ei} 1 / 2}$ tumors [23, 24]. For Class $\mathrm{Di}_{1 / 2}$ tumors that extend intradurally, a multidisciplinary procedure involving neurosurgeons is necessary. Fisch Class $\mathrm{Di}_{3}$ tumors are primarily treated with palliative RT. In our cohort, Class C tumors were mainly resected via an infratemporal approach, whilst for Class $\mathrm{De}_{1 / 2}$ tumors, the approach again varied broadly. The incidence of post-operative $\mathrm{CN}$ palsies and other complications in patients with intracranial, but extradural extension $\left(\mathrm{De}_{1 / 2}\right)$ was no higher than in those with less extensive tumors.

Surgery on tympanic PGLs will directly improve the clinical situation of the patient with minimal risks of $\mathrm{CN}$ damage. Thus, surgical indications are not the same for tympanic, as they are for more wide-spread JTPGLs. It is technically possible to operatively remove the tumor radically even in the most wide-spread intracranially invading tumors. However, even with the most advanced surgical techniques, the risks of permanent deficits of CNs VII and IX-XI are very high. The rates of $\mathrm{CN}$ deficits following aggressive surgery are described in publications of the world's most operatively oriented clinics [18]. With Fisch Class A and B tumors, radical operative eradication of the tumor is the preferred choice. If the tumor is larger and invading into the CNs IX-XI, the risk-benefit ratio of the radical operation should be profoundly discussed with the patient and the other treatment options (subtotal resection and post-operative radiotherapy if needed; radiotherapy alone or, and in certain cases, a wait-and-scan policy) considered.

While the surgical techniques have remained largely the same in the past 40 years at our institution, we make practical suggestions based on our operative experiences of JTPGLs. The importance of pre-operative DSA cannot be overemphasized; it ensures adequacy of venous supply on the contralateral side, which minimizes the risk of cerebral infarction [25]. Transposition of the facial nerve is not essential; keeping the nerve in its bony recess is often enough to preserve intact neural function while allowing superior and inferior approach to the tumor (the so-called fallopian bridge technique) [26]. Blind-sac closure of the external ear is not necessary if no CSF fistula is seen during the operation, but should be undertaken when a fistula is seen or when the risk of it is high. In general, the external auditory canal can be preserved when there is "minimal middle ear extension and limited involvement of the carotid artery" [27]. When handling the internal jugular vein, we recommend packing the cranial end of the sigmoid sinus instead of ligating it and ligating the caudal end [28]. To avoid backpressure and unnecessary intraoperative bleeding, distal occlusion of the jugular vein should be performed just before the tumor is removed [29]. If a tympanic PGL does not invade into the chorda tympani nerve, the nerve should be preserved. If invasion into the nerve is noticed, the nerve should be resected. In most cases, the symptoms following unilateral resection of the chorda tympani nerve (e.g. taste disturbances) are temporary and will be enbursed by the function of the contralateral chorda tympani nerve. An interesting, recent study explores taste function after chorda tympani resection further [30].

RT has shown promising local control rates and few complications compared to surgery in the treatment of HNPGLs [31]. RT is believed to induce an obliterative endarteritis with resultant fibrosis; this may prevent regrowth of the tumor and promote partial tumor involution $[32,33]$. Two patients in the current study received primary RT and for both, no new growth in the tumor was seen at 2 years post-RT. While the first patient wanted no followup, the second suffered a long-term CN XII palsy postRT_albeit with normal swallowing function. Patient 21 (Table 4) developed a new CN VII palsy 2 years after secondary RT with no new growth in the tumor. In a review by $\mathrm{Hu}$ and Persky, $1 \%$ of cranial neuropathies were noted to worsen after RT, while Powell et al. report 2 new $\mathrm{CN}$ VII deficits (2/46, $4 \%$ ) post-RT [34-37]. With appropriate dosing and modern treatment regimens RT is customarily 
well tolerated with complications mostly limited to local irritations. Still, new CN complications remain a possibility post-RT.

Ahmad et al. recommend extending the post-operative follow-up for JTPGLs to at least 10 years after primary surgery [11]. Based on our data of 40 years, multiple Fisch Class B-D tumors showed recurrence after several years of follow-up. In one primary $B_{1}$ tumor, a recurrence was seen after 14 years. There were no recurrences in Class A tumors in our cohort. We thus agree with Ahmed et al. and recommend a follow-up of at least 10 years for Class B-D tumors. Follow-up for Class A tumors can be shorter as long as the tumor resection has been radical.

\section{Conclusion}

In the treatment of JTPGLs, we opt for radical surgery when complete removal of the tumor is possible. In cases of inoperable tumors, we consider primary RT, which has shown great potential for local tumor control. When CNs VII-XII are in danger, our choice is function-preserving surgery with or without adjuvant RT. With long enough post-operative follow-up the residuals and recurrences can be dealt with and patients maintain their maximum qualityof-life, devoid of unnecessary $\mathrm{CN}$ palsies, and further dangers of high risk surgery. Overall, the treatment of JTPGLs in our institution has become more conservative over the years.

\section{Compliance with ethical standards}

Conflict of interest The authors declare that they have no conflict of interest.

Ethical approval This article does not contain any studies with human participants or animals performed by any of the authors.

\section{References}

1. Baysal BE (2002) Hereditary paraganglioma targets diverse paraganglia. J Med Genet 39:617-622

2. Martin TP, Irving RM, Maher ER (2007) The genetics of paragangliomas: a review. Clin Otolaryngol 32:7-11

3. Boedeker CC, Ridder GJ, Schipper J (2005) Paragangliomas of the head and neck: diagnosis and treatment. Fam Cancer 41:55-59

4. Fliedner SM, Lehnert H, Pacak K (2010) Metastatic paraganglioma. Semin Oncol 37:627-637

5. DeLellis R, Lloyd R, Heitz P (2004) World Health Organization classification of tumours. Iarc Press, Lyon

6. Künzel J, Iro H, Hornung J, Koch M, Brase C, Klautke G, Zenk J (2012) Function-preserving therapy for jugulotympanic paragangliomas: a retrospective analysis from 2000 to 2010. Laryngoscope 122:1545-1551

7. Fisch U (1988) Microsurgery of the skull base. Thieme, Stuttgart
8. Shin SH, Sivalingam S, De Donato G, Falcioni M, Piazza P, Sanna M (2012) Vertebral artery involvement by tympanojugular paragangliomas: management and outcomes with a proposed addition to the fisch classification. Audiol Neurootol 17:92-104

9. Charlson ME, Pompei P, Ales KL, MacKenzie CR (1987) A New method of classifying prognostic comorbidity in longitudinal studies: development and validation. J Chronic Dis 40:373-383

10. House JW, Brackmann DE (1985) Facial nerve grading system. Otolaryngol Head Neck Surg 93:146-147

11. Ahmad R, Sivalingam S, Konishi M, De Donato G, Sanna M (2013) Oncologic outcomes in surgical management of jugular paraganglioma and factors influencing outcomes. Head Neck 35:527-534

12. Cheesman AD, Kelly AM (2009) Rehabilitation after treatment for jugular foramen lesions. Skull Base 19:99-108

13. Willen SN, Einstein DB, Maciunas RJ, Megerian CA (2005) Treatment of glomus jugulare tumors in patients with advanced age: planned limited surgical resection followed by staged gamma knife radiosurgery: a preliminary report. Otol Neurotol 26:1229-1234

14. Cosetti M, Linstrom C, Alexiades G, Tessema B, Parisier S (2008) Glomus tumors in patients of advanced age: a conservative approach. Laryngoscope 118:270-274

15. Ivan ME, Sughrue ME, Clark AJ, Kane AJ, Aranda D, Barani IJ, Parsa AT (2011) A meta-analysis of tumor control rates and treatment-related morbidity for patients with glomus jugular tumours. J Neurosurg 114:1299-1305

16. Forbes JA, Brock AA, Ghiassi M, Thompson RC, Haynes DS, Tsai BS (2012) Jugulotympanic paragangliomas: 75 years of evolution in understanding. Neurosurg Focus 33:E13

17. Suárez C, Rodrigo JP, Bödeker CC, Llorente JL, Silver CE, Jansen JC, Takes RP, Strojan P, Pellitteri PK, Rinaldo A, Mendenhall WM, Ferlito A (2013) Jugular and vagal paragangliomas: systematic study of management with surgery and radiotherapy. Head Neck 35:1195-1204

18. Bacciu A, Medina M, Ait Mimoune H, D’Orazio F, Pasanisi E, Peretti G, Sanna M (2015) Lower cranial nerves function after surgical treatment of Fisch Class C and D tympanojugular paragangliomas. Eur Arch Otorhinolaryngol 272:311-319

19. Arístegui Ruiz MÁ, da Costa Belisario J, Martinez Guirado T, Scola Yurrita B (2015) Head and neck paragangliomas: Experience in 126 patients with 162 tumours. Acta Otorrinolaringol Esp. doi:10.1016/j.otorri.2014.11.002 [Epub ahead of print]

20. Wanna GB, Sweeney AD, Carlson ML, Latuska RF, Rivas A, Bennett ML, Netterville JL, Haynes DS (2014) Subtotal resection for management of large jugular paragangliomas with functional lower cranial nerves. Otolaryngol Head Neck Surg 151:991-995

21. Larouere MJ, Zappia JJ, Wilner HI, Graham MD, Lundy LB (1994) Selective embolization of glomus jugulare tumours. Skull Base Surg 4:21-25

22. Murphy TP, Brackmann DE (1989) Effects of preoperative embolization on glomus jugulare tumours. Laryngoscope 99:1244-1247

23. Boedeker CC (2011) Paragangliomas and paraganglioma syndromes. Laryngorhinootologie 90:S56-S82

24. Schipper J, Spetzger U, Tatagiba M, Rosahl S, Neumann HP, Boedeker CC, Maier W (2009) Juxtacondylar approach in temporal paraganglioma surgery: when and why? Skull Base 19:43-47

25. Lustiq LR, Jackler RK (1996) The variable relationship between the lower cranial nerves and jugular foramen tumors: implications for neural preservation. Am J Otol 17:658-668

26. Pensak ML, Jackler RK (1997) Removal of jugular foramen tumors: the fallopian bridge technique. Otolaryngol Head Neck Surg 117:586-591 
27. Moore MG, Netterville JL, Mendenhall WM, Isaacson B, Nussenbaum B (2016) Head and neck paragangliomas: an update on evaluation and management. Otolaryngol Head Neck Surg 154:597-605

28. Jacker RK (2008) Atlas of skull base surgery and neurotology. Thieme, Stuttgart

29. Inserra MM, Pfister M, Jackler RK (2004) Anatomy involved in the jugular foramen approach for jugulotympanic paraganglioma resection. Neurosurg Focus 17:E6

30. Doty RL, Heidt JM, MacGillivray MR, Dsouza M, Tracey EH, Mirza N, Bigelow D (2016) Influences of age, tongue region, and chorda tympani nerve sectioning on signal detection measures of lingual taste sensitivity. Physiol Behav 155:202-207

31. Smee RI, Jayasekara J, Williams JR, Hanna C (2015) Paragangliomas: presentation and management by radiotherapy at the Prince of Wales Hospital. J Med Imaging Radiat Oncol 59:229-235
32. Spector GJ, Compagno J, Perez CA, Maisel RH, Ogura JH (1975) Glomus jugulare tumors: effects of radiotherapy. Cancer 35:1316-1321

33. Vanmiert PJ (1964) The treatment of chemodectomas by radiotherapy. Proc R Soc Med 57:946-951

34. Hu K, Persky MS (2003) The multidisciplinary management of paragangliomas of the head and neck, Part 2. Oncology (Williston Park) 17:1143-1153

35. Powell S, Peters N, Harmer C (1992) Chemodectoma of the head and neck: results of treatment in 84 patients. Int $\mathrm{J}$ Radiat Oncol Biol Phys 22:919-924

36. Dawes PJ, Fillippou M, Welch AR, Dawes JD (1987) The management of glomus jugulare tumours. Clin Otolaryngol $12: 15-24$

37. Lybeert ML, van Andel JG, Eijkenboom WM, de Jong PC, Knegt P (1984) Radiotherapy of paragangliomas. Clin Otolaryngol 9:105-109 